\title{
Raskausajan ja synnytyksen jälkeisen masennuksen ja ahdistuneisuuden varhaista hoitoa tulee tehostaa
}

Sekä naiset että miehet voivat sairastua raskausajan ja synnytyksen jälkeiseen masennukseen, jonka esiintyvyys on noin 10-20 prosenttia (O'Hara \& McCabe 2013) kehittyneissä maissa. Coxin ja kollegojen (2016) mukaan terveydenhuollossa kuitenkin tunnistetaan arviolta alle puolet raskaana olevien ja synnyttäneiden naisten masennustapauksista ja alle 10 prosenttia sairastuneista saa suositusten mukaista hoitoa.

Tuoreen järjestelmällisen katsauksen (Holopainen \& Hakulinen 2019) mukaan sekä masennukseen sairastuneet naiset että miehet kokevat itsensä yksinäiseksi ja tuntevat saavansa riittämättömästi apua puolisoltaan ja muilta läheisiltään. Naiset kuvasivat masennuksen kokemustaan seikkaperäisemmin ja monivivahteisemmin kuin miehet, jolloin miesten kohdalla masennus voi jäädä kokonaan tunnistamatta tai avunsaantiin tulee viive. Myös käsitys siitä, että hyvä vanhempi ei tarvitse tai hae apua saattaa viivästyttää avun pyytämistä ja sen saantia.

Uuden kotimaisen tutkimuksen (Kiviruusu ym. 2020) mukaan sekä äitien että isien masennusoireet olivat suhteellisen pitkäkestoisia loppuraskaudesta lapsen toiseen elinvuoteen saakka ja yhden vanhemman masennus lisäsi riskiä myös toisen masentuneisuudelle. Äitien lievätkin pitkäkestoiset masennusoireet (Pietikäinen ym. 2020) liittyivät kaksi- ja viisivuotiaiden lasten lisääntyneisiin tunne-elämän ongelmiin, kuten ahdistuneisuuteen, surullisuuteen, käytös- ja ylivilkkausoireisiin.

Vanhempien ahdistuneisuusoireita ei ole tutkittu yhtä paljon kuin masennusoireita, vaikka arviolta joka viides äiti sairastuu ahdistuneisuushäiriöön. Ahdistuneisuusoireet voivat olla fyysisiä (esim. sydämentykytys, vapina ja painontunne rintakehällä), psykologisia (esim. jatkuva huoli, ajatusten kiihtyminen ja mielen pyyhkiytyminen tyhjäksi) tai käyttäytymiseen liittyviä (esim. tilanteiden välttely, pakonomainen tarkistelu ja rituaalit). Jopa 40 prosentilla (Jennings ym. 1999) masentuneista äideistä on arvioitu olevan pakonomaisia ajatuksia, kuten pelkoja lapsen vahingoittamisesta.

Kiintymyssuhde lapsen ja vanhemman välillä muodostaa perustan lapsen psyykkiselle kehitykselle sekä myöhemmille ihmissuhteille. Suhde lapseen alkaa muodostuu äidin mielessä jo raskausaikana, ja jatkuu lapsen ensimmäisinä elinkuukausina dynaamisessa vuorovaikutuksessa lapsen kanssa. Perinataaliajan masennus ja ahdistuneisuus voivat häiritä tätä psykologista prosessia. Isän psykologinen kypsyminen vanhemmuuteen ja parisuhteen tilanne vaikuttavat myös suuresti perheen vointiin. Paitsi masennuksen tai muun mielenterveyshäiriön vaikeusastetta, myös vanhempien vuorovaikutusta lapsen kanssa on arvioitava, koska puutteet vuorovaikutuksessa heijastuvat nopeasti lapseen. Toisaalta lämmin vanhemmuus, arjen sujuminen ja hyvä kiintymyssuhde suojaavat lasta vanhemman vakavankin mielenterveyshäiriön vaikutuksilta.

\section{EHDOTUKSIA MASENNUKSEN JA AHDISTUNEISUUDEN VARHAISEN TUNNISTAMISEN JA HOIDON TEHOSTAMISEKSI}

Tarvitsemme Suomeen kliinisen hoitosuosituksen perinataaliajan mielenterveyshäiriöiden varhaiseen tunnistamiseen ja hoitoon vastaavasti kuten on Australiassa (COPE 2017) ja Iso-Britanniassa (NICE 2014). Suositus mahdollistaisi optimaalisen näyttöön perustuvan hoidon varmistamisen.

Lievä ja keskivaikea masennus sekä ahdistuneisuus on mahdollista seuloa ja hoitaa perusterveydenhuollossa, jolloin säästytään kalliimmilta erikoissairaanhoidon kustannuksilta. Neuvolassa masennusta seulotaan EPDS-mielialalomakkeella. Meidän kannattaisi australialaisten tapaan seuloa rutiinisti myös psykososiaalisia ris- 
kitekijöitä esimerkiksi ANRQ-kyselyllä (Austin ym. 2013) rinnakkain EPDS:n kanssa. Kyselyt eivät kuitenkaan korvaa kliinistä arviota tilanteesta. Oleellisinta on luoda vastaanotolle ilmapiiri, jossa vanhempi uskaltaa puhua voinnistaan syyllistymättä sekä ymmärtää, että masennuksen lisäksi on myös useita muita mielenterveydenhäiriötä $(\mathrm{mm}$. traumaperäiset häiriöt, kaksisuuntainen mielialahäiriö, erilaiset ahdistuneisuushäiriöt, persoonallisuushäiriöt), jotka voivat haitata vuorovaikutusta lapsen kanssa ja vaikuttaa koko perheen hyvinvointiin.

Jos vanhemman perinataaliajan mielenterveyshäiriö täyttää erikoissairaanhoidon kriteerit, myös vuorovaikutusta kannattaisi arvioida ja hoitaa samassa hoitopaikassa. Parhaiten tämä onnistuisi integroimalla lastenpsykiatrista ja varhaisen vuorovaikutuksen psykoterapiaosaamista Perinataalipsykiatriseen (raskaus- ja vauva-ajan mielenterveyshäiriöiden hoitoon erikoistuneeseen) erikoissairaanhoidon tiimiin. Myös perustasolle tarvitaan sekä yksilö-, ryhmä- että paripsykoterapeuttisia interventioita. Interpersoonallisesta (Sockol 2018) ja kognitiivis-behavioraalisesta psykoterapiasta (Stuart \& Koleva 2014) on hyvää näyttöä perinataaliajan masennuksen ja lupaavaa näyttöä myös ahdistuneisuuden hoidossa. Kumppaneiden mukaan ottamisen on myös havaittu helpottavan äitien masennusoireita yksi- löinterventioita paremmin (Misri ym. 2000).

Ensimmäinen psykiatrinen äiti-vauva-osasto perustettiin Iso-Britanniaan 1948. Parhaillaan perinataalipsykiatria on hakemassa tai jo saavuttanut suppean erikoisalan aseman mm. Australiassa, Ranskassa, Isossa-Britanniassa ja Kanadassa. Yhteensä 33 maata osallistui kansainvälisen artikkelin (Brockington ym. 2017) kirjoittamiseen äiti-lapsi-psykiatrian ydinasioista - samanaikainen hoitovastuu sekä äidistä että lapsesta yhtenä tärkeimmistä.

Perinataaliajan mielenterveyshäiriöiden ennuste on hyvä ja niiden varhainen tunnistaminen ja hoito on kustannusvaikuttavaa (McDaid ym. 2019). Iso-Britanniassa tehtyjen laskelmien (Bauer ym. 2014) mukaan hoitamattomista perinataalipsykiatrisista häiriöistä aiheutuvien haittojen hoito tulee julkiselle sektorille viisi kertaa kalliimmaksi kuin järjestää suositusten mukainen hoito; yli 70 prosenttia hoitamattomiin häiriöihin liittyvistä kustannuksista arviointiin tulevan lapselle aiheutuneista haitoista. Pietikäisen ja kollegojen (2019) pääkirjoituksessa hahmotellaan Suomen olosuhteisiin sopivaa perinataalipsykiatrista hoitojärjestelmää. Kysymys kuuluukin: onko meillä varaa olla panostamatta perinataaliajan mielenterveyshäiriöiden ja vanhempilapsi-vuorovaikutuksen hoitoon?

\section{LÄHTEET}

Austin MP, Colton J, Priest S, Reilly N, Hadzi-

Pavlovic D. The antenatal risk questionnaire (ANRQ):

Acceptability and use for psychosocial risk assessment in the maternity setting. Women and Birth. 2013; 26: 17-25. doi:10.1016/j.wombi.2011.06.002

Bauer A, Parsonage M, Knapp M, Iemmi V, Adelaja B. The cost of perinatal mental health problems. LSE \& Centre for Mental Health; 2014. https:// www.centreformentalhealth.org.uk/sites/default/ files/2018-09/costsofperinatal.pdf

Brockington, Butterworth, Glangeaud-Freudenth. An international position paper on mother-infant (perinatal) mental health, with guidelines for clinical practice. Arch Womens Ment Health (2017) 20:113120.

COPE, Center of Perinatal Excellence. Mental health care in the perinatal period. Australian clinical practice guideline. October 2017. https://www.cope.org.au/ wp-content/uploads/2018/05/COPE-Perinatal-MHGuideline_Final-2018.pdf

Cox EQ, Sowa NA, Meltzer-Brody SE, Gaynes BN. The perinatal depression treatment Cscade: Baby

steps toward improving outcomes. J Clin Psychiatry 2016;77:1189-1200. doi: 10.4088/JCP.15r10174.

O'Hara MW, McCabe JE. Postpartum depression: current status and future directions. Annual Review of Clinical Psychology 2013; 9:379-407.

Holopainen A \& Hakulinen T. New parents' experiences of postpartum depression: a systematic review of qualitative evidence. JBI Database System Rev Implement Rep 2019;17:1731-1769.

Jennings KD, Ross S, Popper S, Elmore M. Thoughs for harming infants in depressed and in nondepressed mother. J Affect Disord 1999;21:21-28.

doi: 10.1016/s0165-0327(98)00185-2.

Kiviruusu O, Pietikäinen JT, Kylliäinen A, Pölkki P, Saarenpää-Heikkilä O, Marttunen M, Paunio T, Paavonen EJ. Trajectories of mothers' and fathers' depressive symptoms from pregnancy to 24 months postpartum. J Affect Disord 2020;1:629-637. doi: 10.1016/j.jad.2019.09.038.

McDaid D, Park AL, Wahlbeck K. The economic case for the prevention of mental illness. Annu Rev Public Health 2019;40:373-389. 
Misri S, Kostaras X, Fox D, Kostaras D. The impact of partner support in the treatment of postpartum depression. Can J Psychiatry 2000;45:554-558.

NICE, National Institute for Health and Care Excellence. Antenatal and postnatal mental health: clinical management and service guidance. 2014, updated in 2018. https://www.nice.org.uk/guidance/ cg192

Pietikäinen J, Taka-Eilola T, Paunio T. Suomeen tarvitaan perinataalipsykiatriaa. Lääketieteellinen Aikakauskirja Duodecim 2019;135:1809-1811.

Pietikäinen JT, Kiviruusu O, Kylliäinen A, Pölkki P, Saarenpää- Heikkinen O, Paunio T, Paavonen EJ. Maternal and paternal depressive symptoms and childrens' emotional problems at the age of 2 and 5 years: A longitudinal study. J Child Psychol Psychiatry 2020;61:195-204. doi: 10.1111/jcpp.13126.

Sockol LE. A systematic review and meta-analysis of interpersonal psychotherapy for perinatal women. J Affct Disord 2018;232:316-328. doi: 10.1016/j.jad.2018.01.018.
Stuart S, Koleva H. Psychlogical treatments for perinatal depression. Best PractRes Clin Obstet Gynaecol 2014;28:61-70.

doi: 10.1016/j.bpobgyn.2013.09.004.

\section{Johanna PietikäInen}

LL, Psykiatriaan erikoistuva lääkäri, Vieraileva tutkija,

Helsingin yliopistollinen sairaala ja Helsingin yliopisto, Psykiatria,

Terveyden ja hyvinvoinnin laitos (THL),

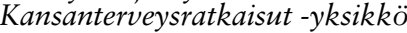

\section{TuOvi Hakulinen}

TtT, Dosentti, Tutkimuspäällikkö, Terveyden ja hyvinvoinnin laitos (THL), Lapset, nuoret ja perheet $-y k s i k k \ddot{~}$

\author{
Arja Holopainen \\ TtT, Johtaja, \\ Hoitotyön tutkimussäätiö (Hotus), \\ Suomen JBI ybteistyökeskus
}

